\title{
Struktur Komunitas Plankton di Inlet dan Outlet Danau Rawa Pening
}

\author{
Riche Hariyati, Erry Wiryani dan Yunita Kus Astuti, \\ Laboratorium Ekologi dan Biosistematik Jurusan Biologi FMIPA Undip
}

\begin{abstract}
Rawa Pening is a natural lake that has 17 inlet (rivers thats lead water into lake) and one outlet Tuntang River Inlet and outlet of Rawa Pening Lake have differences in physico-chemistry factor and covering of plant water. Plankton is one of organism that influenced by this condition.

The aim of this research is to establish structure community of plankton in inlet and outlet Rawa Pening Lake. Sample was taken from 7 inlet (the downstream of Segalok, Torong, Panjang, Galeh, Rengas, Kedungringis and intercourse of Parat, Legi and Muncul downstream). Sample of outlet taken from upstream of Rawa Pening Lake, around of port and before bridge. Sample then analyzed by diversity index, similarity index, equaliy index, and total individu per liter. Seventy seven plankton were found in inlet and outlet Rawa Pening Lake. Sixty five species are phytoplankton and contains of 22 species Chlorophyceae, 38 species Bacillaryophyceae, 2 species Cyanophyceae, 2 species Euglenophyceae and one species of Chrysophyceae. 12 species are zooplankton and contains of 10 species Rotifera also one species Sarcomastigophora and one species of Copepoda. Based on diversity index, equality index, and total individu the community structure of plankton in inlet is relatively stabil than in outlet Rawa Pening Lake.The similarity index showed that the level of species similarity is low. This is indicated that structure community of plankton in inlet and outlet is different.
\end{abstract}

Key words: Rawa Pening, Plankton, Community

\section{PENDAHULUAN}

Sebagai suatu ekosistem danau, Rawa Pening berfungsi sebagai sumber air yang paling praktis dan murah untuk kepentingan domestik maupun industri dan sebagai sistem pembuangan yang memadai dan paling murah. Sebagai sumber air paling praktis danau sudah menyediakannya melalui terkumpulnya air secara alami melalui aliran permukaan yang masuk ke danau, aliran sungai-sungai yang menuju ke danau dan melalui aliran dibawah tanah (Kumurur,2002). Akan tetapi fungsi-fungsi tersebut pada danau Rawa Pening menjadi terganggu karena adanya tumbuhan air yang tumbuh memenuhi sebagian besar perairan tersebut.

Keberadaan tumbuhan air akan berpengaruh terhadap keseluruhan ekosistem pada perairan tersebut. Salah satu komponen ekosistem yang terpengaruh oleh kondisi tersebut adalah plankton.

Kondisi ekosistem danau Rawa Pening tak lepas dari pengaruh kondisi sungai-sungai yang mengalir masuk (inlet) ke dalam danau Rawa Pening. Rawa pening sendiri merupakan hulu dari DAS Sungai Tuntang. Ada 17 sungai yang menjadi inlet bagi Rawa Pening dan satu-satunya sungai yang merupakan outlet dari Rawa pening adalah Sungai Tuntang. Tujuan dari penelitian ini adalah untuk mengkaji struktur komunitas plankton baik pada inlet maupun outlet danau Rawa pening.

\section{BAHAN DAN METODE}

Bahan dan alat yang digunakan pada penelitian ini adalah formalin $10 \%$, plankton net size 25, mikroskop, botol sampel, akuades, label, dan SRCC. Pada penelitian ini, diambil tujuh inlet dari keseluruhan inlet yang ada yaitu meliputi : muara Sungai Torong (stasiun.A), muara Sungai Segalok (stasiun.B), muara Sungai Panjang (stasiun.C), muara Sungai Galeh (stasiun.D), muara Sungai Kedungringin (stasiun.E) serta pertemuan dari Sungai Parat, Muncul dan Legi (stasiun.F). Pengambilan sampel hanya meliputi muara-muara tersebut. Hal ini karena persentase penutupan tumbuhan airnya relatif lebih kecil jika dibandingkan dengan muara yang lain. Sedangkan pada daerah outlet diambil tiga daerah pengambilan sampel, yang meliputi daerah 
keluarnya air danau (outlet danau Rawa Pening/ stasiun $\mathrm{H}$ ), daerah didekat dermaga (stasiun.I) dan daerah disekitar jembatan (stasiun.J).

Pengambilan sampel dilakukan dengan tiga kali ulangan. Perhitungan dan analisis sampel biologi dan kimia di lakukan di Laboratorium Ekologi dan Biosistematika Jurusan Biologi Universitas Diponegoro.

\section{Cara Kerja}

Pada tiap stasiun diambil sampel air sebanyak 50 liter, kemudian disaring dengan plankton net size 25 , hasil saringan dimasukkan kedalam botol sampel 100 ml.Dari sampel tersebut diidentifikasi jenis-jenis planktonnya.

Pada saat pengambilan sampel diukur juga faktor-faktor fisik-kimia perairan antara lain : DO, suhu, kecerahan dan $\mathrm{pH}$ perairan. Pengukuran turbiditas dilakukan di laboratorium. Plankton dianalisa menggunakan indeks keanekaragaman Shannon-Wiener, indeks perataan jenis, indeks kesamaan jenis, kemelimpahan relatif dan jumlah individu per liternya.

\section{HASIL DAN PEMBAHASAN}

Dari hasil penelitian ditemukan 77 spesies plankton, terdiri atas kelompok phytoplankton 65 spesies dan zooplankton 12 spesies. Spesies phytoplankton yang ditemukan selama penelitian terdiri dari Kelas Chlorophyceae 22 spesies, Kelas Bacillaryophyceae 38 spesies, dua spesies dari Kelas Cyanophyceae, dua spesies dari Kelas Euglenophyceae dan satu spesies Kelas Chrysophyceae. Dari 12 spesies yang diketemukan pada kelompok zooplankton, sepuluh (10) spesies diantaranya merupakan kelompok Rotifera. Sedangkan kelompok Copepoda dan Sarcomastigophora masing-masing hanya ditemukan satu spesies. Dari jenis-jenis phytoplankton yang ditemukan tersebut, Bacillaryophyceae adalah kelompok yang paling sering dijumpai dengan spesies yang paling banyak dijumpai adalah Synedra affinis, Synedra ulna, Melosira varians dan Tabellaria sp. Menurut Hutchinson (1975), spesies-spesies tersebut merupakan Diatomae (Bacillaryophyceae) yang umum ditemui pada perairan tawar dan bersifat planktonik. Tingginya jumlah diatom seperti Asterionella, Fragillaria, Synedra spp,
Stephanodiscus spp, dan Melosira spp merupakan indikasi tingginya produktifitas suatu danau dan kebanyakan dari beberapa genera tersebut umum ditemukan pada danau oligotrofik dan eutrofik.

Zooplankton yang paling sering ditemukan adalah Mesocyclops leuckartii (Copepoda) dan Centrophyxis aculecta (Rotifera). Diantara kedua spesies tersebut, Mesocyclops relatif lebih tinggi jumlah spesiesnya. Menurut Sastrodiharjo(1997), tingginya jumlah Copepoda disebabkan oleh melimpahnya bahan makanan yang tersedia. Makanan tersebut dapat berasal dari partikel tumbuhan dan hewan kecil, sisa-sisa bahan organik maupun detritus yang terbawa oleh arus dan terakumulasi di bagian muara sungai.

Densitas Plankton di Inlet dan Outlet Danau Rawa Pening

Densitas plankton pada inlet dan outlet danau Rawa Pening ditunjukkan pada gambar 1 dibawah ini:

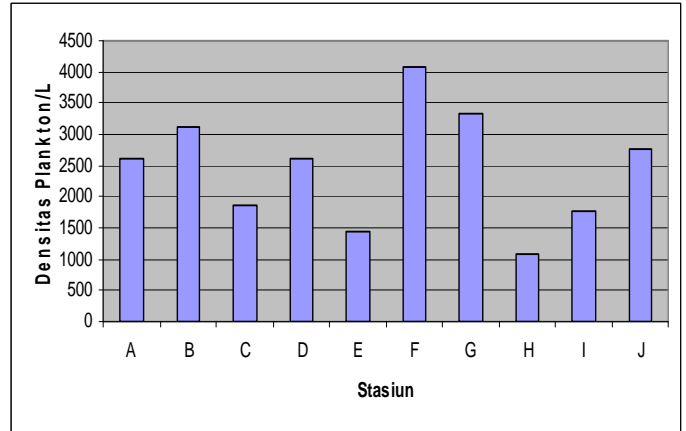

Keterangan :

Inlet : A, B, C, D, E, F, G

Outlet : H. I, J

Gambar 1. Grafik Densitas plankton pada inlet dan outlet danau Rawa Pening

Berdasarkan grafik, pada inlet danau Rawa Pening densitas terendah dijumpai pada stasiun E (daerah muara Sungai Rengas) yaitu sebesar 1429,13 individu/L dan densitas tertinggi dijumpai pada stasiun $\mathrm{F}$ (daerah pertemuan muara 3 Sungai, yaitu Legi, Parat dan Muncul) sebesar 4070,87 individu/L. sedangkan pada oulet, densitas tertinggi dijumpai pada stasiun $\mathbf{J}$ (daerah setelah jembatan) yaitu sebesar 2772 individu/liter dan densitas terendah dijumpai pada stasiun $\mathrm{H}$ (outlet danau rawa pening) sebesar 1083 individu/liter. Rendahnya densitas disebabkan karena rendahnya jumlah individu pada suatu populasi yang akhirnya 
akan mempengaruhi rata-rata pertumbuhan populasi. Sakah satu faktor yang menyebabkan densitas plankton pada stasiun E (inlet muara sungai Rengas) menjadi rendah adalah rendahnya nilai kecerahan. Kecerahan menunjukkan banyak sedikitnya intensitas cahaya matahari yang masuk pada suatu badan air. Menurut Payne (1986), kepadatan populasi plankton dapat menurun secara tiba-tiba. Beberapa faktor yang menyebabkan penurunan densitas tersebut adalah faktor fisik seperti rendahnya intensitas cahaya yang masuk dan faktor kimia, misalnya kurangnya nutrien atau akumulasi bahan yang bersifat racun.

\section{Keanekaragaman Jenis Plankton di Inlet dan Outlet Danau Rawa Pening}

Nilai indeks keanekaragaman ShannonWiener pada inlet Rawa Pening selengkapnya disajikan dalam grafik berikut ini:



Keterangan :

Inlet : A, B, C, D, E, F, G

Outlet: H. I, J

Gambar 2. Grafik Indeks Keanekaragaman ShanonWiener pada inlet-outlet danau Rawa Pening

Berdasarkan grafik tersebut maka dapat diasumsikan bahwa keanekaragaman jenis plankton pada inlet dan outlet danau Rawa Pening termasuk sedang. Magguran (1988) menyatakan bahwa keanekaragaman jenis dikatakan sedang jika nilai indeks keanekaragaman berkisar antara 1,0 - 3,0. Stasiun G (daerah muara Sungai Kedungringis) mempunyai indeks keanekaragaman yang paling rendah yaitu 1,65. Salah satu faktor fisik-kimia yang mempengaruhi komunitas plankton adalah DO (dissolved oxygen atau kadar oksigen terlarut). Nilai DO (konsentrasi oksigen terlarut) pada stasiun ini menunjukkan nilai 0. Pada kondisi ini, hanya spesies dengan daya adaptasi yang tinggilah yang mampu hidup. Sehingga keanekaragaman jenisnya menjadi rendah.

Tertutupnya sebagian besar permukaan air oleh tumbuhan air merupakan salah satu sebab rendahnya jumlah spesies pada stasiun ini. Menurut Odum (1993), beberapa jenis ganggang yang dijumpai terapung pada zona litoral dan limnetik akan berasosiasi atau terikat dengan tanaman yang berakar, ini merupakan ciri utama zona litoral. Beberapa tipe ganggang yang utama pada keadaan tersebut adalah kelompok Bacillaryophyceae yang meliputi Asterionella, Navicula, Synedra dan Fragillaria. Phylum Chlorophyceae yang umum dijumpai pada zona ini adalah ganggang yang bentuk selnya filamen, seperti Spirogyra, Zygnemopsis, dan Oedogonium.

Indeks keanekaragaman terbesar dijumpai pada stasiun $\mathbf{J}$ (dearah Sungai Tuntang setelah jembatan) yaitu sebesar 2,811. Besarnya nilai indeks keanekaragaman pada daerah ini kemungkinan besar disebabkan oleh tingginya konsentrasi nitrogen dan fosfor. Kedua unsur ini merupakan sumber nutrien bagi plankton.

Phytoplankton maupun zooplankton yang ditemukan pada outlet menunjukkan keanekaragaman yang relatif kecil. Menurut Payne (1986), hal ini terjadi karena terdapat penurunan konsentrasi beberapa ion organik seperti phospat, nitrat dan nitrit pada sungai-sungai yang berhubungan dengan danau terutama pada bagian hulu sungai sehingga terdapat penurunan jumlah biomassa plankton.

\section{Perataan Jenis-jenis Plankton di Inlet dan Outlet Danau Rawa Pening}

Guna mengetahui variasi dari nilai indeks Perataan Jenis plankton pada inlet dan outlet danau Rawa Pening, dapat dilihat pada grafik berikut ini : 


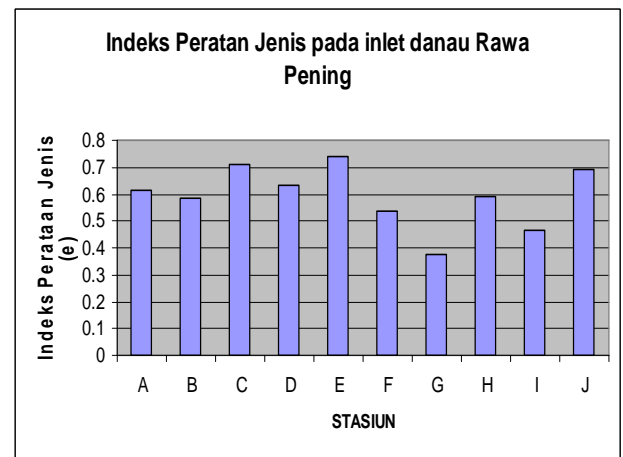

Keterangan :

Inlet : A, B, C, D, E, F, G

Outlet : H. I, J

Gambar 3. Grafik Indeks Perataan Jenis pada inlet outlet danau Rawa Pening

Berdasarkan grafik diatas, dapat diasumsikan bahwa jenis-jenis plankton yang hidup pada inlet dan outlet Rawa Pening tidak tersebar secara merata. Salah satu faktor penyebabnya adalah adanya dominansi beberapa spesies plankton pada komunitas tersebut seperti Zygnemopsis sp, Ankistrodesmus sp,Pinnularia gibba, Synedra spp dan Mesocyclops leuckartii.

Nilai indeks Perataan jenis pada inlet dan outlet relatif kecil. Nilai indeks terkecil dijumpai pada stasiun $\mathrm{G}$ (daerah muara sungai Kedungringis) sebesar 0.379 sedangkan nilai indeks terbesar dijumpai pada stasiun E (daerah muara sungai Rengas) sebesar 0.791. Indeks perataan jenis bersama-sama dengan indeks keanekaragaman Shannon-Wiener digunakan untuk menggambarkan distribusi organisme pada komunitasnya. Dengan melihat hubungan tersebut, maka distribusi jenis-jenis plankton pada inlet Kedungringis tidak merata pada seluruh komunitasnya.

\section{Tingkat Kesamaan Jenis-jenis Plankton di Inlet dan Outlet Danau Rawa Pening}

Tingkat kesamaan komunitas antara inlet dan outlet dihitung dengan menggunakan indeks similaritas. Hadi (2002), menyatakan bahwa indeks kesamaan (similarity index) digunakan untuk membandingkan kesamaan spesies organisme yang ditemukan pada suatu habitat dengan habitat yang lain. Makin tinggi nilai indeks kesamaan antara dua habitat maka tingkat kesamaannya spesiesnya juga makin besar. Beberapa stasiun yang mempunyai nilai indeks yang besar $(50 \%)$ diantaranya adalah : stasiun B (daerah inlet Sungai Torong) dengan stasiun G (daerah inlet Sungai Kedungringin) dan stasiun I (daerah sungai Tuntang sebelum jembatan) dengan stasiun A (daerah muara sungai Segalok). Akan tetapi dengan nilai indeks kesamaan jenis sebesar 50\% masih dianggap mempunyai tingkat kesamaan jenis yang relative rendah. Menurut Magguran (1988), tingkat kesamaan jenis dianggap besar jika nilai indeksnya berkisar antara $61 \%$ sampai dengan $99 \%$.

Sedangkan stasiun dengan nilai indeks kesamaan jenis yang paling kecil ditemukan pada stasiun H (daerah outlet Sungai Tuntang) dengan stasiun B (muara Sungai Torong) yaitu sebesar 7\%. Rendahnya nilai indeks antara ke dua daerah ini karena stasiun $\mathrm{H}$ (daerah outlet Sungai Tuntang) merupakan daerah hulu dari sungai sementara itu stasiun B (muara Sungai Torong) merupakan daerah muara sungai. Perbedaan ini tentu saja akan mempengaruhi jenis-jenis spesies plankton maupun kepadatannya pada dua komunitas tersebut.

\section{KESIMPULAN}

1. Pada inlet dan outlet danau RawaPening ditemukan 77 jenis plankton. 65 diantaranya merupakan phytoplankton dan 12 jenis merupakan zooplankton. Zygnemopsis $s p$ merupakan phytoplankton yang paling dominan pada kedua daerah tersebut.

2. Struktur komunitas plankton pada inlet relatif lebih stabil jika dibandingkan dengan outlet berdasarkan pada nilai indeks keanekaragaman jenis Shannon-Wiener, perataan jenis, jumlah total individu per liter (densitas plankton) serta kemelimpahan relatifnya.

3. Berdasarkan indeks kesamaan jenis, daerah inlet dan outlet danau Rawa Pening mempunyai tingkat kesamaan jenis yang rendah.

\section{DAFTAR PUSTAKA}

Ambarwati, E, 1997, Kelimpahan dan Keanekaragaman Plankton pada Zonasi yang Berbeda di Perairan Waduk Gajah 
Mungkur Wonogiri, Skripsi Jurusan Biologi, Fakultas MIPA, Universitas Diponegoro, Semarang

Anonim, 1992, Polusi Air dan Udara, Penerbit Kanisius, Yogyakarta

Apriyanto, E dan Liviawati, 1992, Pengendalian Hama dan Penyakit Ikan, Penerbit Kanisius, Yogyakarta

Asmawi, 1986, Kunci Identifikasi Plankton, Penerbit UI Press, Jakarta.

Battish, S., K, 1992, Freshwater Zooplankton of India, Oxford and IBH Publishing, New Delhi

Brower, E, J., et al., 1989, Field and Laboratory Methods For General Ecology third edition. Wm. C. Brown Publisher. United States America.

Campbell, A, N., et al., 2003, Biology Concepts and Connections fourth edition, Benjamin Cummings, San Fransisco

Darley, M.W., 1982, Alga Biology: Aphysiological Approach, Blackwell Scientific Publications

Garno,S.,Y,1999, Studi Evaluasi Penggunaan Plankton-Net Pada Sample Fitoplankton dalam Analisis Status Lingkingan Ekosistem Perairan, Jurnal Sains dan Teknologi Indonesia vol.1 no.5. Hlm 146-155

Goldman, R, C., dan Horne, J, A., 1983, Lymnology, Mc Graw-Hill inc, New York

Goltenboth, F., dan Kristyanto, I, A., 1994, Fisherish In Lake Rawa Pening Java Indonesia Fact and Prospect, Satyawacana University Press, Salatiga

Hadi,M.,Wiryani, E., Heru, S, N., 1997, Ekologi, Jurusan Biologi F. MIPA UNDIP, Semarang

Hutchinson, G.E., 1975, A Treatise of Lymnology, Vol III-Limnologycal Botany, John Wiley and Sons, London

Isnansetyo,A.,K, 1995, Teknik Kultur Phytoplankton dan Zooplankton, Pakan Alami untuk Pembenihan Organisme Laut, Penerbit Kanisius, Yogyakarta

Kumurur, A, V., 2002, Aspek Strategis Pengelolaan Danau Tondano Secara Terpadu, Ekoton Vol 2, No 1:73-80

Listiawati, 2001, Distribusi Vertikal Phytoplankton di Perairan Waduk Mrica Banjarnegara, Skripsi Jurusan Biologi,
Fakultas MIPA, Universitas Diponegoro, Semarang

Magguran,A.E., 1988, Ecological Diversity and Its Measurement, Chapman and hall

McNaughton, S., J, 1990, Ekologi Umum edisi kedua, Gadjah Mada University Press, Yogyakarta

Michael,P., 1995, Metode Ekologi untuk Peyelidikan Lapangan dan Laboratorium, UI Press, Jakarta

Moss, B., 1980, Ecology of Freshwater, Blackwell Scientific Publications, London

Novitasari, D, 2005, Komunitas Plankton di Sungai Banger Pekalongan berdasarkan Empat Indeks Keanekaragaman, Skripsi Jurusan Biologi, Fakultas MIPA, Universitas Diponegoro, Semarang

Nybakken,J.W., 1988, Biologi Laut, Suatu Pendekatan Ekologi, Pt. Gramedia, Jakarta

Odum, E.P., 1993, Dasar-dasar Ekologi, Penerbit UGM, Yogyakarta

Payne, A.I., 1986, The Ecology of Tropical Lakes and Rivers, JohnWiley and Sons, New York.

Polunin, Nicholas, 1990, Pengantar Geografi Tumbuhan dan Ilmu-ilmu Serumpun, Gadjah Mada University Press, Yogyakarta

Prawiro, S, 1992, Polusi Air dan Udara, Penerbit Kanisius, Yogyakarta

Qiptiyah M, 2003, Peranan Keanekaragaman Fitoplankton sebagai Bioindikator Lingkungan dalam Pengelolaan Ekosistem Lahan Basah, Eboni no 9. hlm 10-16

Resosoedarmo, S., 1989, Pengantar Ekologi, Remaja Karya, Bandung.

Ricklefs, E., R, 1999, Ecology $4^{\text {th }}$ edition, W.H Freeman and Company, New York

Sastrodihardjo, S., 1997, Kepadatan Berbagai Kelompok Zooplankon di Danau Rawa Pening, Laporan Penelitian Fakulatas Sains dan Matematika, Universitas Kristen Satya Wacana, Salatiga.

Silalahi, U. Adiganda., 1989, Periodisitas Plankton di Danau Rawa Pening, Program Studi Ekologi Akuatik, Fakultas Biologi, Universitas Kristen Satya Wacana.

Soeprobowati, T, R., 2004, Optimasi Fungsi Danau Sebagai Mikrokosmos, Perhimpunan Biologi Indonesia Cabang Yogyakarta, UGM Press, Yogyakarta 
Suriawiria,U., 1993, Mikrobiologi air, Penerbit Alumni, Bandung

Sze,P., 1993, A Biology of The Algae, Wn.C. Brown publisher,Inc

Wetzel, E.R., 1983, Lymnologycal Analyses, Springer-Verlag, New York
Whitten, T., 1996, The Ecology of Java and Bali, Periplus Edition, Dalhousie University. 